\title{
Controlling excess water production in fractured carbonate reservoirs: chemical zonal protection design
}

\author{
Bisweswar Ghosh ${ }^{1} \cdot$ Samhar Adi Ali ${ }^{1} \cdot$ Hadi Belhaj $^{1}$
}

Received: 14 July 2019 / Accepted: 3 January 2020 / Published online: 31 January 2020

(c) The Author(s) 2020

\begin{abstract}
Fractured carbonate reservoirs are prone to premature water cut production at the early stage of recovery. Conventionally completed long horizontal wells, suffering from high water cut through fracture networks, need reliable and cost-effective treatment solutions to control water entry, without damaging oil-saturated segments. Protection of oil flow channels from polymer gel invasion could be a challenge in complex fractured reservoirs because of the enormity of the number of zones that may require damage protection. In this work, a chemical package system is developed, comprising three different chemical solutions. The first fluid is designed to protect the low-permeable oil-saturated zones by creating an impermeable barrier while keeping the water conductive fractures open, followed by a gelant, designed to invade, solidify, and seal off the water conductive fractures. The third treatment is designed for a complete dissolution of the protective barrier created by the first fluid. The effectiveness of this process is evaluated through a set of four core flood studies at reservoir conditions. It was observed that whereas the effective brine permeability could be reduced by $74-91 \%$, oil effective permeability is reduced by $12-17 \%$ depending on the fracture aperture. The paper also discusses the key parameters to be addressed for successful field implementation of this technology.
\end{abstract}

Keywords Water shutoff $\cdot$ Fractured reservoir $\cdot$ High water cut $\cdot$ Polymer gel $\cdot$ Formation damage

\section{Introduction}

High water cut oil production is an economic setback for the operating company, and with the advent of long horizontal extended reach drillings (ERD), controlling high water cut is becoming an even greater challenge. ERD wells with measured depth (MD) of 40,320 ft and horizontal section of 35,770 ft in Al-Shaheen field, located in Qatar offshore and 41,667 ft long with a horizontal section of $38,514 \mathrm{ft}$ in Sakhalin, Russia (Satter and Iqbal 2016), are some of the examples of modern days drilling trends. Maersk Oil is the undisputable leader in drilling ERD wells with an average length of reservoir section reaching beyond 15,000 ft (Rushmore Reviews 2017). These wells are generally completed with casing/pre-drilled liners with downhole flow controllers and sensors to mitigate permeability heterogeneity and

Bisweswar Ghosh

bisweswar.ghosh@ku.ac.ae

1 Petroleum Engineering Department, Khalifa University, SAN Campus, P.O. Box 2533, Abu Dhabi, United Arab Emirates early water production issues. However, most of the earlier generation wells of lesser horizontal reach (2000-5000 ft) are not equipped to handle water encroachment downhole. Water influx can occur through several mechanisms, and the monitoring and management of these wells are a significant challenge. It is often very difficult and expensive to obtain accurate diagnostics in the complex flow regimes, particularly in fractured formations, where water production can be encountered earlier than expected (Sarkar et al. 2002). In fractured carbonate reservoirs, water coning is a major contributor to high water cut and a very challenging issue, both in terms of simulation and actual control. This phenomenon is dominated by viscous and gravitational forces. If reliable reservoir properties are known, simulation modeling can help in determining optimum production rate and cone progress during production (Perez et al. 2012). Inamullah et al. (2015) have shown through simulation that optimum oil production rate is to be reduced to half of that of maximum production rate if the coning effect is to be minimized. Controlling water coning in fractured reservoirs is more challenging than the homogeneous reservoirs because of the rapid movement of water through the fractures (Reda

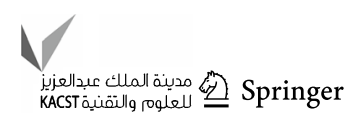


2016). To counter the problem, Dabiri et al. (2017) suggested the benefits of horizontal wells over vertical wells, showing (through simulation) that critical oil production rate in horizontal wells is greater than that of vertical wells in fractured formations. However, the problems may be further aggravated due to faulty well trajectory or strong acid treatment, resulting in rapid deterioration of well performance. Fang et al. (2017) addressed a similar problem for a gas reservoir. Their observation differs from that of Reda is that, whereas Reda (2016) claims that oil reservoir aquifer strength has a little effect on produced water cut, Fang et al. (2017) found great impact of aquifer size and strength on gas productivity and water cut, possibly because of higher dissolved gas in water.

From the above discussion, it is apparent that timely and appropriate remedial action in controlling excess water production is crucial for improving well performance and saving the wells from premature closure (Al-Shabibi et al. 2012). Controlling water production in complex horizontal wells with the existing conductive fractures, especially vertical ones, such as in fractured carbonate reservoirs, is an extremely difficult task to perform.

Placing downhole zonal isolation tools (packer, bridge plugs, etc.) for the purpose of water control could be economical only when there are a limited number of water conductive channels, and the locations and geometry of the features are well defined which is rarely seen in fractured carbonate reservoirs. Controlling excess water production through polymer gel squeeze could invite irreversible damage to the well unless the oil-producing segments are identified and protected from gel entry. Though water shutoff (WSO) successes in horizontal wells are rather limited, several rigless water shutoff successes have been reported from Saudi Arabian oil fields (Nasr-El-Din et al. 1998) and elsewhere. In almost all these incidences, only the toe sections of the wells are shut off using either bridge plug or throughtubing inflatable packers, with or without cement support.

In some cases, a rigid gel is placed ahead of the cement slurry to facilitate cement squeeze (Al-Zubail et al. 2003). Although inflatable packers alone are not the best solution for shutting off water conductive zones, it has produced good results when placed in combination with cement or crosslinked rigid gel (Taoutaou 2013). In most cases, cross-linked polymer gel is preferred because of several advantages over cement slurry (Bedaiwi et al. 2009). Coil tubing-assisted gel placement in horizontal wells is reported by Lymar (2011) in Belarusian oil fields. Field production results and detail of the placement are not discernible from this report, though.

It is evident from the literature that rigless application of cross-linked polymer gel is limited to bullheading technique with little control on the gel movement path and hence highly unreliable (Burrafato et al. 1999; El-Karsani et al. 2014). In complex fractured reservoirs with extended reach horizontal and multilateral wells, the challenges are severe and often insurmountable, such as (a) identifying multiple water entry paths which are not contributing to hydrocarbon production, (b) applying right volume of the right type of gelant, (c) determining gel squeeze pressure, and (d) most importantly the protection of oil-saturated/producing zones from being damaged by gelant invasion.

Mechanism of fluid flow through fractured carbonate formations is often very complex due to the fracture network or complex porosity types present in these reservoirs (Belhaj et al. 2003). The enormity of the complex structure of a carbonate reservoir could be visualized through the given sample image (Fig. 1). Besides, the strong acids used during post-drilling wellbore cleanup or matrix stimulation are known to create wormholes/channels connecting the underlain aquifer.

High water cut production is a major concern in matured fields. A large number of research projects have been undertaken, and several methods have been suggested for field implementation (Alaa et al. 2008, 2013). Though the techniques found merits in theory and laboratory tests, in field trials, most of them are found to be either ineffective or damaging. It is believed that, since gels are water-based solutions, they would preferentially enter high water-saturated zones (Chauveteau 2004; Xianchao et al. 2014). However, in detail analysis, it is seen that the gelant penetration distances were not much different in high oil and high water-saturated zones (Liang et al. 1993). As a result, bullheading treatment has resulted in almost uniform damage to all zones (Turner and Nwaozo 2010). Rigless gallant placement could be favorable in a stratified reservoir with vertical discontinuity where the formation pressure of the oil-saturated stratum

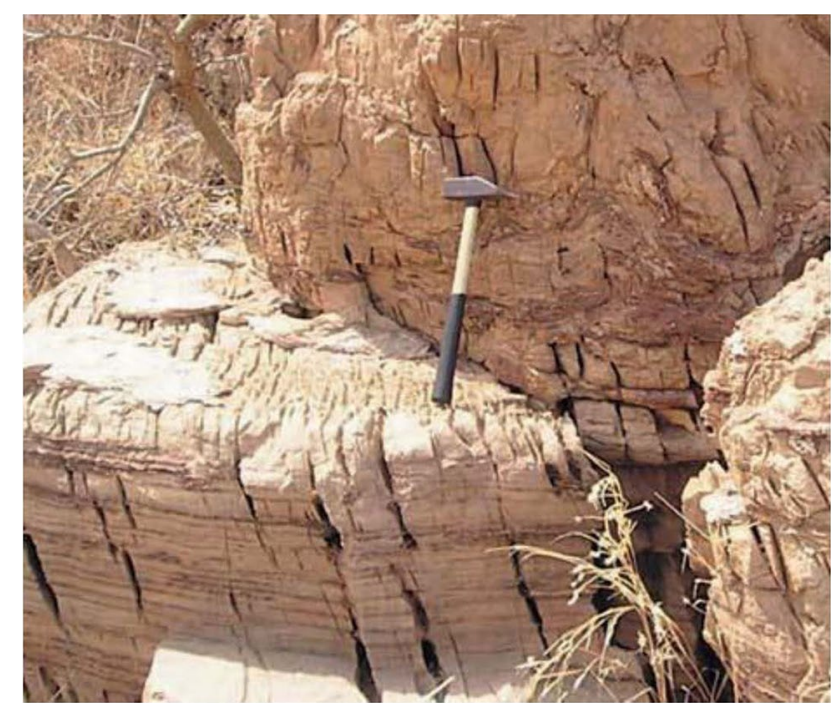

Fig. 1 Complex fracture network of a carbonate sedimentary outcrop (Whaley 2008) 
is greater than the high-permeability waterflooded strata. Selective placement of gel may be achievable by injecting the gelant at a pressure higher than the high permeability water producing zone but lesser than the oil-saturated formation (Seright 1995). Sharifpour et al. (2015) tested a cation/ salinity sensitive biopolymer gel, which can be bullheaded based on the assumption that the water-bearing zone has low pressure and the water salinity is higher than the high-pressure zone. It also incorporated a protective gas flow during the placement as an added factor. Laboratory glass micromodel experimental results indicated success; however, the process is not verified in the field. This method, however, is not applicable when water is moving through fractures or high-permeability streaks and vertically communicating water-bearing channels.

In view of the limitations of gelant-based water shutoff methods described above and the enormous opportunities exist due to the number of problematic horizontal wells throughout the world, we developed a novel water control system with the following objectives.

- It should be a low-cost rigless water control treatment option, without the necessity of special downhole zonal isolation devices.

- The treatment should have longevity no less than 6 months.

- The treatment solution should effectively seal large water conductive fractures without sealing oil conducting micro-fractures and matrices.

- The treatment should result in significant control in water production without sacrificing hydrocarbon production.

\section{Materials and methods}

The treatment is designed to be executed in sequence, with three purpose-based treatment fluids. The role of the first fluid would be to create a plaster impermeable to the gelant on the oil-producing micro-fracture rock fabrics, while allowing passage for plugging-type gelant fluid through larger water conductive fractures, thus protecting the areas of interest. The technique relies on the bridging ability of the suspended particles present in the first fluid, designed based on fracture aperture distribution. The particles need to be small enough to be able to invade the tinctures, but large enough to plug the micro-fractures, thus facilitating the formation of an impermeable external filter cake. This step would be followed by placement of a suitable gelant, capable of forming a rigid and long-lasting rigid gel compatible with carbonate reservoir environment. The gelant would penetrate and seal only the large fractures, as the microfractures are now impermeable to gelant solution. This step would be followed by a two-stage cleaning process. After the flushing of the remaining gelant materials from hole, an enzyme-based-chemical breaker solution, designed to dissolve the plastering cake material, would be placed. Based on the productivity test, a second step clean up with a mild acid solution may be placed for improved productivity. The treatment fluids are designed considering the chemical environment and high-temperature sustainability in a carbonate reservoir. The following materials and methods are used to accomplish the tasks.

\section{Well and reservoir parameters}

Reservoir formation in consideration for this study is a giant fractured carbonate reservoir situated in the Middle East. Numerous fractures ranging from a few microns to millimeters are observed on the horizontal pay section of the wells. Well and reservoir parameters relevant to this study are given in Table 1. Based on the reservoir and well information, the constraint set for this study was:

(1) Static reservoir temperature: $100{ }^{\circ} \mathrm{C}$.

(2) Fractures responsible for water conductivity are above $200 \mu \mathrm{m}$ in aperture.

(3) Reservoir pressure is above bubble point and contains no separate gas phase.

(4) Static reservoir pressure is $4000 \mathrm{psi}$, and the fracture initiation pressure is above $6000 \mathrm{psi}$.

(5) The specific gravity of treatment fluids should be less than 1.1 to avoid loss.

Table 1 Well and reservoir parameters

\begin{tabular}{ll}
\hline Parameters & Descriptions/values \\
\hline Formation lithology & $\begin{array}{c}\text { Calcite }(94 \%), \\
\text { dolomite }(4 \%) \\
\text { with minor clay } \\
(<2 \%)\end{array}$ \\
Average permeability & $200 \mathrm{mD}$ \\
Minimum permeability & $2 \mathrm{mD}$ \\
Maximum permeability & $900 \mathrm{mD}$ \\
Average porosity & $23 \%$ \\
Porosity range & $19-27 \%$ \\
Reservoir temperature & $100{ }^{\circ} \mathrm{C}$ \\
Static reservoir pressure & $4000 \mathrm{psi}$ \\
Fracture initiation pressure & $>6000 \mathrm{psi}$ \\
Length of horizontal section & $3000 \mathrm{ft}$ horizontal \\
& section, seg- \\
& mented at every \\
Average oil production/well & $300 \mathrm{ft}$ \\
Average water production/well & $2400 \mathrm{BOPD}$ \\
Gas liquid ratio & $1280 \mathrm{BWPD}$ \\
\hline
\end{tabular}


(6) The well is completed with pre-drilled liner (PDL) and has full accessibility to the coil tube.

(7) The $3000 \mathrm{ft}$ horizontal section is segmented at every $300 \mathrm{ft}$ interval; thus, segmented treatment is possible.

\section{Core selection and core preparation}

Core plugs used in this study are cut from a single block of about $1.2 \mathrm{ft}$ long core. The core samples were subjected to a two-stage cleaning process using Soxhlet extractors and various solvents. In the first stage of cleaning, toluene is used to remove organic materials present in the pores. The extraction was continued until the effluent was visibly clear. The cores were then removed, dried, and placed in the second unit having methanol as solvent, to extract the inorganic salts (API RP-40). Plugs were dried in a hot air oven at $90{ }^{\circ} \mathrm{C}$ for a duration not less than $36 \mathrm{~h}$, and a minimum of three weights were taken to confirm the completion of the process. Subsequently, their petrophysical properties were measured (Table 2). Afterward, the plugs were cut longitudinally into two halves using blades of different thicknesses. The pieces were then combined together with the help of plastic heat shrink (Fig. 2). Fracture of different aperture sizes was created by placing sand spacers of different grain sizes in between the two halves. The fracture width was determined by the optical stereomicroscope. Fracture permeability of the pre-treated cores was measured following the procedure suggested by Salimi and Alikarami (2006), using the empirical equation,

$K_{\mathrm{f}}=W_{\mathrm{f}}^{3} / 3 \pi D$

where $K_{\mathrm{f}}$ is the effective permeability of the fracture, $W_{\mathrm{f}}$ is the average fracture aperture, and $D$ is the diameter of the core.

\section{Brine}

As a general-purpose brine, $3 \% \mathrm{KCl}$ in deionized water was used for the entire study. The brine is filtered through a 0.45 - $\mu \mathrm{m}$ filter before use.

\section{Crude oil}

Light crude oil of 0.65 ( $\mathrm{mPa}$ s) viscosity and 39.8 API gravity (at $100{ }^{\circ} \mathrm{C}$ ) is used. The oil is vacuum-degassed and filtered through $2-\mu \mathrm{m}$ filter and stored in a sealed container in a nitrogen environment for later uses.

Table 2 Petrophysical properties of the test core plug

Core plug\# Length $(\mathrm{cm}) \quad$ Diameter $(\mathrm{cm}) \quad$ Porosity $(\%) \quad K_{\text {wabs }}(\mathrm{mD}) \quad K_{\mathrm{o}}$ at $S_{\text {wirr }}(\mathrm{mD}) \quad K_{\mathrm{w}}$ at $S_{\text {or }}(\mathrm{mD}) \quad$ Fracture width $(\mu \mathrm{m}) \quad$ Calculated fracture perm

(D)

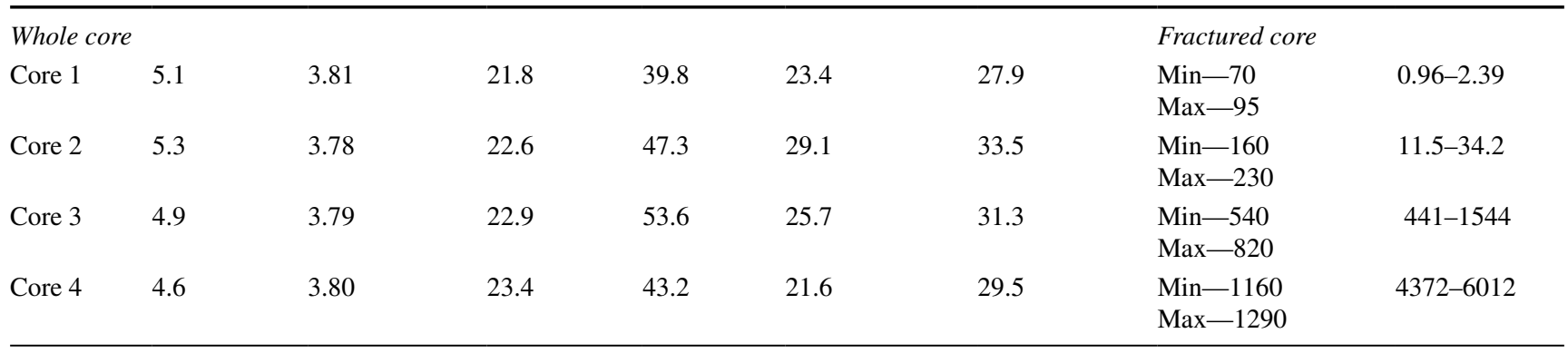
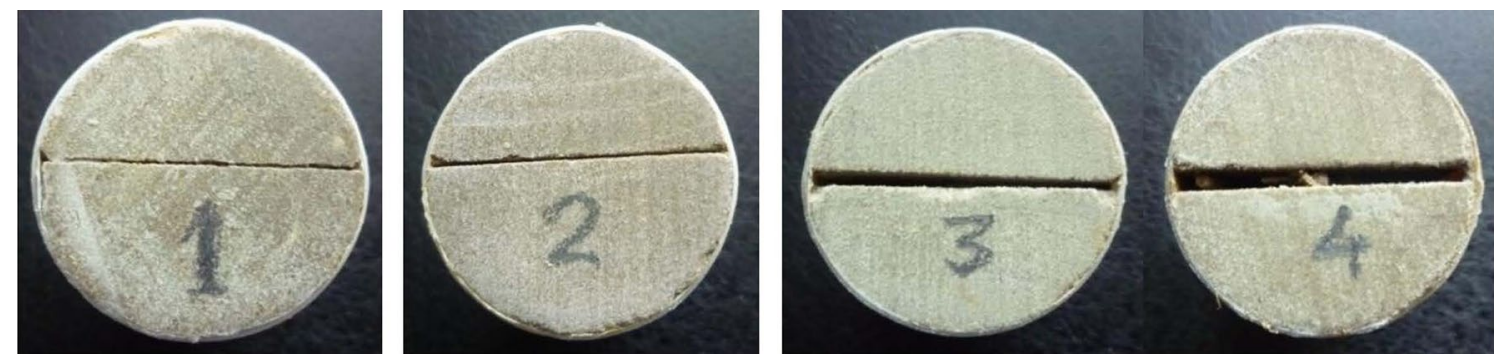

Fig. 2 Top face of the fractured core plugs 


\section{The plastering/protecting fluid (Fluid-1)}

The working principle of this fluid is similar to the nondamaging drill-in fluids, which are generally composed of easily degradable polymeric viscosifiers and rheology builders such as starch, xanthan and poly-anionic cellulose (PAC) along with suspended pore bridging particles (sized $\mathrm{CaCO}_{3}$, used in polymer-based drilling and completion fluids to create a robust cake and arrest fluid loss). Together they build a nearly impermeable semisolid filter cake, which can be removed from the wellbore wall with a specific chemical breaker. The allowable size distribution of bridging solids in drill-in fluid depends on the pore size distribution. If the particles are too small $(<30 \%$ of the median pore throat aperture), they can invade through the pore channels, and if they are too large, a filter cake of high permeability will result. It is suggested that the size distribution of the suspended particle for bimodal and oversized fractured or vugular pore up to $150 \mu \mathrm{m}$ should ideally be that the D90 of the bridging particles should be equal to the common maximum pore sizes (He and Stephens 2011). Based on the fact that the intended function of this fluid would be the ability to form an impermeable cake on the micro-fracture surface while keeping the macro-fractures open for further treatment, the envisaged properties for the design of Fluid-1 were:

(a) The bridging particles must be small enough to flow through the large fractures, thus keeping them open for further flow of gelant fluid.

(b) They must be large enough to bridge the micro-fractures and create an impermeable filter cake to prevent the flow of gelant into the micro-fractures. (c) The filter cake must be easily degradable in order to regain permeability close to the original permeability.

In consideration of the above, the first design step in the process of forming a seal was to determine the largest dominant pore size or fracture width. Figure 3 demonstrates the fracture aperture of the target formation, determined through high-definition formation micro-imaging (FMI-HD) logs (Fig. 4). The bimodal fracture size distribution plot reveals that the average aperture size of the small fractures is close to $300 \mu \mathrm{m}$, whereas the larger fractures are $2000 \mu \mathrm{m}$ and above. Based on the "ideal packing theory" or IPT (Dick et al. 2000), which states that the ideal packing of pores by mud filter cake occurs when the percent of cumulative volume versus the $\sqrt{D}$ forms a straight-line relationship $(\sqrt{D}$ is the square root of the particle diameter). Based on this theory, it has been found that $2-3 \%$ by volume or $60-90 \mathrm{~kg} / \mathrm{m}^{3}$ of a proper blend of bridging agents can provide an optimum seal (BP 1996). To simulate the given reservoir scenario, we created two artificially core plugs with small fractures $(70-230 \mu \mathrm{m})$ and another two with large fractures (500 $\mu \mathrm{m}$ and above). Coarse $(200-250 \mu \mathrm{m})$, medium $(100-120 \mu \mathrm{m})$, and fine (40-70 $\mu \mathrm{m})$ grade $\mathrm{CaCO}_{3}$ were mixed in equal proportion to meet the suggested guidelines. To optimize the blend proportion and volume of $\mathrm{CaCO}_{3}$, we opted HP-HT filter loss method using 10 Darcy permeability ceramic disk, which has a mean pore diameter of about $50 \mu \mathrm{m}$. The composition and properties of the optimized fluid are given in Table 3.

Fracture Aperture Histogram

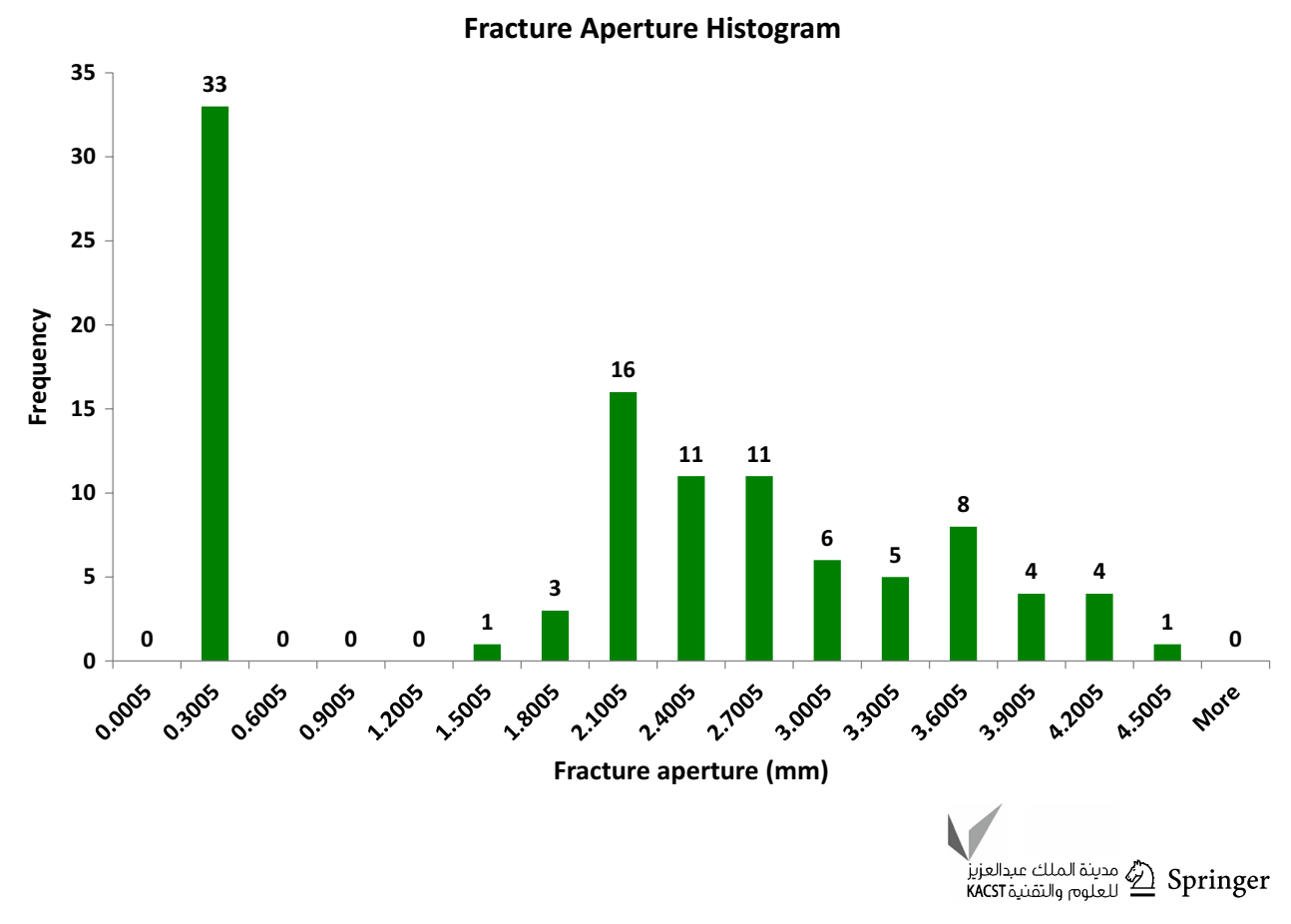

Fig. 3 Fracture aperture histogram derived from the FMI logs 

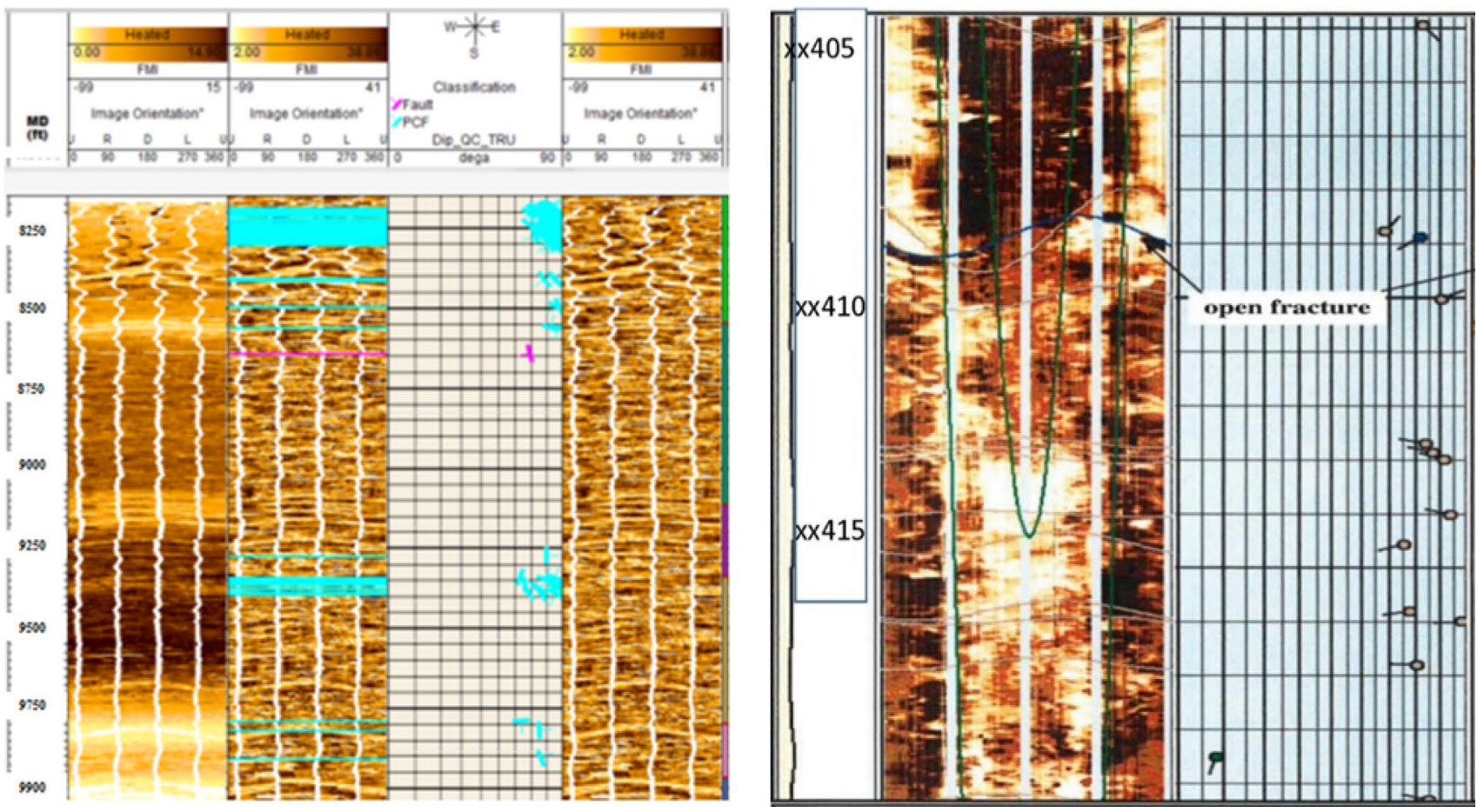

Fig. 4 FMI log of the target formation showing water encroachment (left). 3-D view of a major open fracture (right)

Table 3 Chemical composition of the gelant solution (Fluid-2)

\begin{tabular}{lll}
\hline Chemical & Function & For 1 1 fluid \\
\hline $\mathrm{KCl}$ & Swelling inhibitor & $30 \mathrm{~g}$ \\
$\mathrm{NaOH}$ & $\mathrm{pH}$ control & To adjust to $\mathrm{pH} 9.5$ \\
$\mathrm{CaCO}_{3}(50)$ & Pore bridging agent & $65 \mathrm{~g}$ \\
Xanthan polymer & Viscosifier & $4 \mathrm{~g}$ \\
Starch powder & Binder and rheology builder & $16 \mathrm{~g}$ \\
\hline
\end{tabular}

\section{Fracture sealing gelant (Fluid-2)}

To block the larger open fractures, we needed a robust, thermally stable, high calcium tolerant polymer gel, which would be water-thin solution in its pre-gelled state for ease of squeeze. Low molecular weight (80-100 K Dalton) copolymer of acrylamide and vinyl-pyrrolidone (provides higher thermal stability and high calcium tolerance) was used for preparing the gelant. The thermal stability of the dry polymer is proved to exceed $250{ }^{\circ} \mathrm{C}$, measured through MettlerToledo DSC-TG thermal analyzer (TA8000). Viscosity of the final solution measured with Haake Rotational Viscometer at $100{ }^{\circ} \mathrm{C}$ at D50 was $1.2 \mathrm{cp}$. Hexamine and hydroquinone were used as cross-linking agents (Yadav et al. 2013a, b). The stability and the performance of the gel are evaluated through a series of bottle tests under reservoir temperature and chemical environment. The thermal stability of the final composition concerning mechanical strength was verified (at oven temperature of $100{ }^{\circ} \mathrm{C}$ for 2 months). The gelation time of the final composition (polymer 5\%, hexamine 1\%, and hydroquinone $0.8 \%$ ) was about $10 \mathrm{~h}$ based on the gel viscosity infliction point (Hardy et al. 1998). A sample photograph of the gel is shown in Fig. 5.

\section{Filter cake breaking solution (Fluid-3)}

In order to dissolve the cake forming materials (including starch, xanthan polymer, and $\mathrm{CaCO}_{3}$ particles), a chemical breaker solution was designed following our previous work (Mehtar et al. 2012). The breaker was a mixture of xanthanase (4\%) and amylase (5\%) buffered to $\mathrm{pH} 4$. Optimization of the cleanup solution is conducted in porous ceramic disk following standard HP-HT filtration loss method. Since we failed to achieve satisfactory cleanup with the help of the enzyme-buffer system alone, a second-stage cleanup with $3 \%$ acetic acid was included, which resulted in a highly satisfactory cleanup (Fig. 6).

\section{Core flow studies}

In order to assess the performance of the chemical systems described above, a set of core flow experiments were conducted. The core flow setup is adequately equipped to conduct flow tests both in static and dynamic conditions in order to be able to simulate downhole treatment conditions. Fluid cylinders with floating pistons, connected to ISCO 


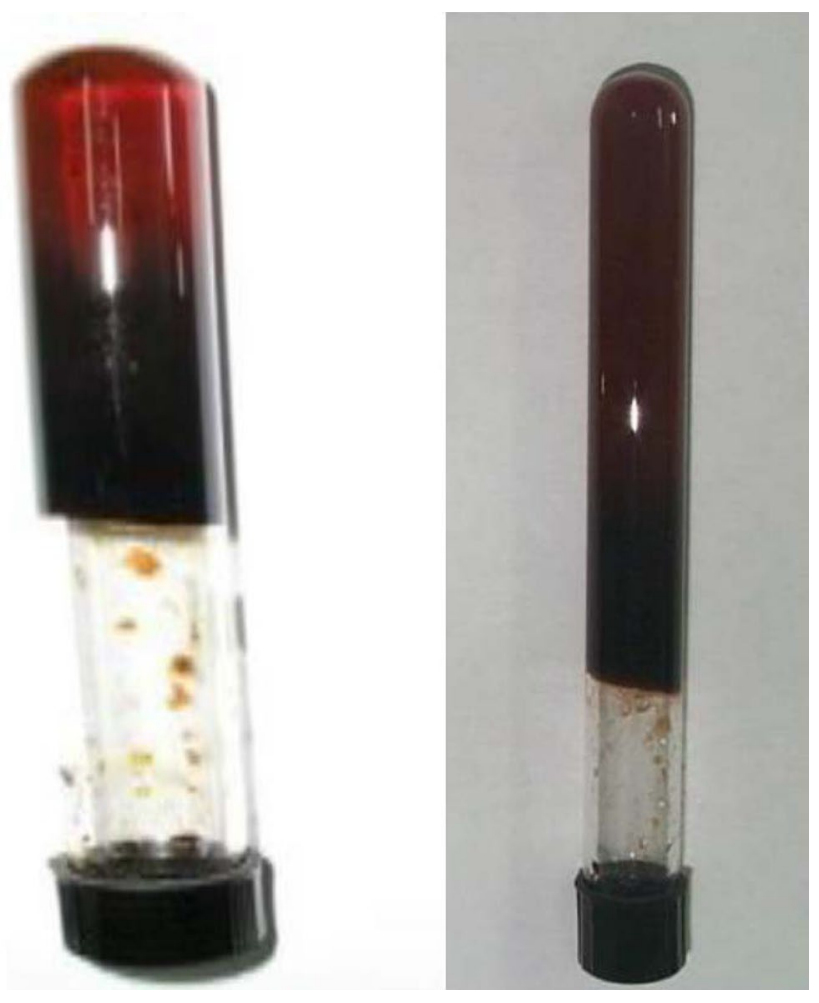

Fig. 5 The cross-linked polymer gel

precession pumps, were used to inject fluids on the core face through the heating loops. The fluids are pumped from both directions, either through the forward direction (wellbore to the reservoir) or through the reverse direction (reservoir to wellbore) to simulate treatment and production conditions, respectively. The entire system was confined in a controlled temperature oven to preheat the fluids and core to desired wellbore temperature. Performance of the three steps WSO treatment design is evaluated based on the changes in return permeability and residual resistance factor both before and after get treatment. The steps involved were as follows:
1. Brine-saturated core samples were loaded into a hydrostatic core holder and applied 500 psi net confining pressure and $100 \mathrm{psi}$ overbalance pressure at stabilized temperature $\left(100{ }^{\circ} \mathrm{C}\right)$

2. Measured $K_{\text {wabs }}$ (absolute permeability to brine), $K_{\text {oeff }}$ @ $S_{\text {wirr }}$ (effective permeability to oil at irreducible brine saturation), and $K_{\text {weff }} @ S_{\text {or }}$ (effective brine permeability at residual oil saturation) from reverse direction at $0.2 \mathrm{ml} / \mathrm{min}$ flow rate. Permeabilities calculated at this stage were considered as matrix permeability.

3. The core plugs were then dislodged from core holder, cut, and packed to create fracture as described previously and brought them to $S_{\text {or }}$ condition again.

4. Circulated Fluid- 1 in the forward direction on a $1 / 2$ " spacer, which acted as wellbore. It was done at $100 \mathrm{psi}$ overbalance pressure in order to allow fluid leak-off toward the upstream end. The flow rate was maintained at $10 \mathrm{ml} / \mathrm{min}$ for $10-12 \mathrm{~min}$. Further, $30 \mathrm{~min}$ of static exposure was given under overbalance for the filter cake to buildup (see the schematics in Fig. 7).

5. Injected two pore volumes of Fluid-2 (fracture sealing gelant) at 10-15 psi differential pressure.

6. Circulated brine on the core face at a high flow rate $(100 \mathrm{ml} / \mathrm{min})$ for about $2 \mathrm{~min}$ keeping the formation side closed.

7. Fluid-3 (filter cake breaking solution) is circulated with an overbalance of $10 \mathrm{psi}$ on the wellbore face for $30 \mathrm{~min}$ at a slow flow rate $(1 \mathrm{ml} / \mathrm{min})$, followed by a static reaction time of $8 \mathrm{~h} .3 \%$ acetic acid replaced the enzyme solution, and further $1 \mathrm{~h}$ of reaction time was allowed. It was observed that there is a fluid leak-off from the other end during the second soak period. Note that fluid leak-off was kept minimum by reducing the overbalance pressure gradually.

8. The system is given a further $12 \mathrm{~h}$ shut-in for completion of cross-linking reactions.
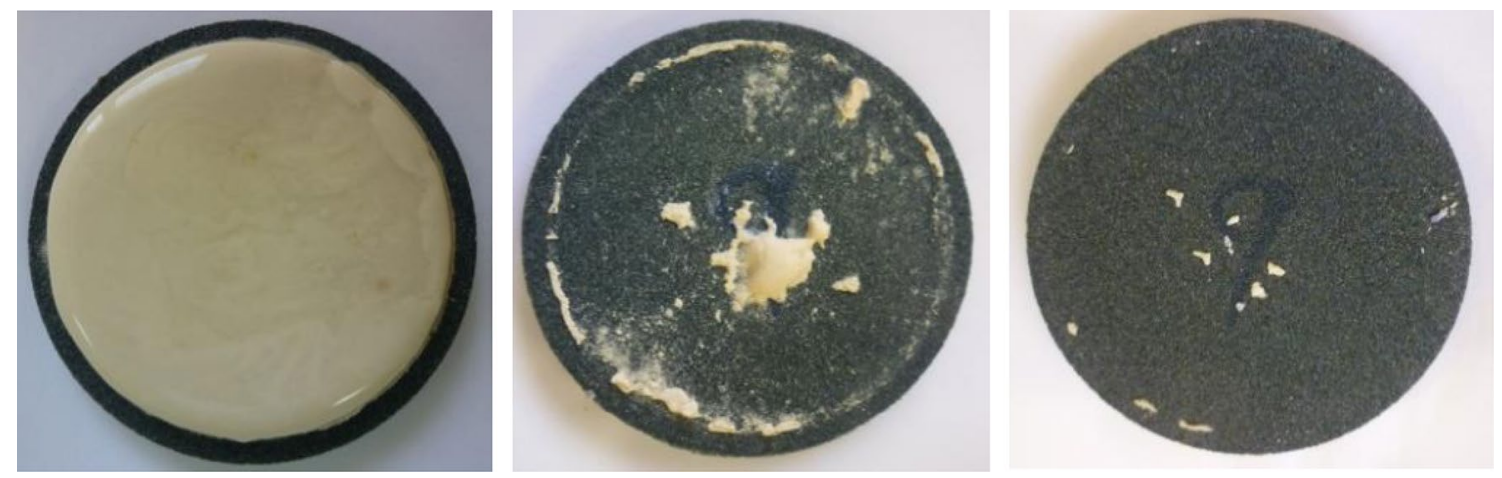

Fig. 6 Demonstration of wellbore cleaning efficiency by the clean-up fluid composition. Initial cake (left); remaining cake after enzyme treatment (center); remaining cake after acetic acid treatment (right) 
Fig. 7 Schematics of core flow design (right—well model and left-core flow model)

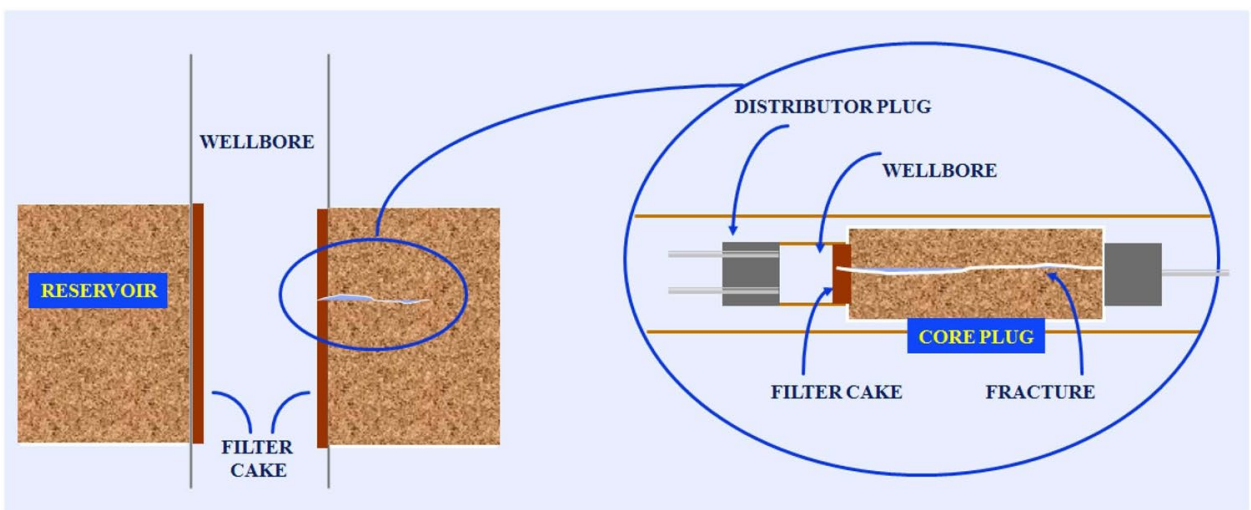

9. Return permeability of the cores was measured from the reverse direction, using brine and oil at the flow rate of $0.5 \mathrm{ml} / \mathrm{min}$ till steady-state pressure is achieved.

10. In polymer gel treatment, gel extrusion pressure or critical pressure $(\mathrm{Pc})$ is an important factor in understanding the sealing strength of the gel. It usually depends on polymer and cross-linking characteristics, adsorption ability on the rock surface, and tortuosity of the fracture. Critical pressure gradient (PL) is a commonly used term, which is defined as the critical pressure per unit plugging length, i.e., $\mathrm{PL}=\mathrm{Pc} / L$ (Seright 2003). Brine was pumped (from the reverse direction), to measure the gel extrusion pressure or critical pressure $(\mathrm{Pc})$; the injection pressure was increased gradually, until there was a sudden pressure drop, indicating extrusion of gel from the fracture. The first onset of pressure drop is considered as Pc

Residual resistant factor of water $\left(F_{\text {rrw }}\right)$ is a widely used quantitative indicator for reduction or enhancement of permeability before and after gel treatment. It is defined as:

$F_{\text {rrw }}=\frac{\lambda_{\mathrm{wi}}}{\lambda_{\mathrm{wa}}}=\frac{K_{\mathrm{wi}}}{K_{\mathrm{wa}}} * \frac{\mu_{\mathrm{wa}}}{\mu_{\mathrm{wi}}}=\frac{K_{\mathrm{wi}}}{K_{\mathrm{w}}}$

where $\lambda_{\mathrm{wi}} / \lambda_{\mathrm{wa}}$ is the ratio of initial water mobility and mobility after gel treatment. $K_{\mathrm{wi}} / K_{\mathrm{wa}}$ is the ratio of water permeability, and $\mu_{\mathrm{wi}} / \mu_{\mathrm{wa}}$ is the ratio of water viscosity. $\mu_{\mathrm{wi}} / \mu_{\mathrm{wa}}$ is considered as 1 , as viscosity of water would not change due to gel treatment.

\section{Results and discussion}

\section{Porous media and fluid selection}

The fracture aperture and fracture permeability of the artificially fractured core plugs are shown in Table 2. It can be noticed that whereas matrix permeability of these core plugs was in the range of $40-50 \mathrm{mD}$, the fracture permeabilities were ranging from 1 to several thousands of Darcies representing a naturally fractured formation. The selection of the right filter cake forming material was also very important in order to protect the matrix area from blocking gel invasion, which is achieved by an optimum blend of suspended particles (sized $\mathrm{CaCO}_{3}$ of fine, medium, and coarse grades). It was screened from several combinations of polymers and $\mathrm{CaCO}_{3}$ grades based on the matrix and fracture aperture so that the small fractures are blocked, but the large fractured remained open. Accordingly, ultrafine grade $\mathrm{CaCO}_{3}$ is selected and optimized the required quantity, which provided the minimum fluid loss (Table 3 ). The gelant used for plugging the fractures is a low-viscous solution at pregelling condition, and after, cross-linking takes the shape of semisolid robust gel (Fig. 3). The gel was found to be stable at reservoir temperature for a long duration (test duration of 60 days). The cleaning compositions were evaluated through HT-HP fluid loss setup using ceramic disks. It can be seen from Fig. 6 that after the second stage cleaning, the disk is almost absolutely clean. On quantitative estimation, about $98 \%$ of the protecting cake is removed from the disks' surface. Thus, a high return permeability could be expected from the treated cores.

\section{Gel treatment results}

Tables 2 and 4 present initial petrophysical properties and the results of the three-stage treatment on the core plugs. The following considerations were made in order to enable treatment evaluation results quantitatively:

1. Matrix permeability is the same as measured permeability of the core.

2. The fracture permeability calculated from fracture aperture was considered as the overall permeability of the fractured core (when a large fracture is present, the flow contribution from the matrix area becomes insignificant). 
Table 4 Measured permeabilities and RRF values (before and after treatment)

\begin{tabular}{lllll}
\hline Measured parameters & Core 1 & Core 2 & Core 3 & Core 4 \\
\hline Pre-treatment matrix brine permeability at $S_{\text {or }}$ (measured) & $27.9 \mathrm{mD}$ & $33.5 \mathrm{mD}$ & $31.3 \mathrm{mD}$ & $29.5 \mathrm{mD}$ \\
Pre-treatment matrix oil permeability at $S_{\text {wirr }}$ (measured) & $23.4 \mathrm{mD}$ & $29.1 \mathrm{mD}$ & $25.7 \mathrm{mD}$ & $21.6 \mathrm{mD}$ \\
Pre-treatment fracture permeability (calculated) & $0.69-2.39 \mathrm{D}$ & $11.5-34.2 \mathrm{D}$ & $441-1544 \mathrm{D}$ & $4372-6012 \mathrm{D}$ \\
Post-treatment brine permeability & 490 & 728 & 35.7 & 94.2 \\
$F_{\text {rrw }}$ of brine $\left(K_{\mathrm{f}}\right.$ pre-treatment $/ K_{\mathrm{w}}$ post-treatment) & $1.95-4.88$ & $15.8-46.97$ & $12 \mathrm{~K}-43 \mathrm{~K}$ & $46 \mathrm{~K}-64 \mathrm{~K}$ \\
Gel critical pressure gradient $(\mathrm{Pc} / L)$ & $57 \mathrm{psi} / \mathrm{ft}$ & $39 \mathrm{psi} / \mathrm{ft}$ & $256 \mathrm{psi} / \mathrm{ft}$ & $164 \mathrm{psi} / \mathrm{ft}$ \\
\hline
\end{tabular}

3. Ultra-high permeability fractures are the main contributors to the produced water. Therefore, initial brine permeability can be considered the same as the fracture brine permeability.

4. Post-treatment brine permeability is the overall permeability of fracture and matrix area.

It is evident from the core flow results presented in Table 4 that the treatment results for Cores 1 and 2, with $W_{\mathrm{f}}$ in the micron range, are different from Cores 3 and 4 with $W_{\mathrm{f}}$ in the millimeter range. For Cores 1 and 2 with low fracture apertures, the $F_{\text {rrw }}$ is between 2 and 47 . Although this value is high, the return permeability is still very high and sufficient to maintain well productivity. It is evident from this result that although there is gel penetration into the fracture, the distance of penetration is not significant enough to block the fractures completely. This finding is also supported by the fact that the critical gel extrusion pressure is low (57 and $39 \mathrm{psi} / \mathrm{ft}$, respectively). For Cores 3 and 4 with larger fracture apertures, the $F_{\text {rrw }}$ is extremely high $(12,000-64,000)$, indicating effective plugging of the fractures. Post-gel treatment brine permeability being close to the initial matrix permeability is indicative of effective sealing of the fractures and efficient cleaning of the protective plaster created on the matrix face. Fracture sealing strength of the gel for Cores 3 and 4 indicated by the critical pressure gradient (PL) is 256 and $164 \mathrm{psi} /$ $\mathrm{ft}$, respectively. Normally water shutoff gel treatments are given up to a distance of $10-15 \mathrm{ft}$ around the wellbore. Thus, the net impact of the developed gel is expected to be 2000 psi or more, which is significantly higher than the available drawdown pressure in most oil reservoirs.

Moreover, in a practical situation, the highly tortuous fracture path is expected to provide higher sealing strength than what is observed in the laboratory on a smoothly cut fracture. From these observations, it can be concluded that the three-stage treatment designed in this work is more effective for large aperture fractures than small fractures. It also demonstrates that the oil-bearing micro-fractures can be protected and rejuvenated with the treatment design described above.

\section{Field application guidelines}

When it comes to fractured reservoirs, many bullhead treatments were proposed and executed earlier. However, it was found either damaging to oil zones or squeeze pressure had been precisely balanced in accordance with the difference between oil and water zone pressures (Johnson Jr 1998; Turner and Nwaozo 2010). Short treatment life and little control on the gel propagation path were also contributing factors for failure of the squeeze jobs (Cheung and Quilter 1998) and lack of patronizing.

Most of the risks associated with bullheading WSO could be eliminated by applying the proposed three-stage WSO treatment, which would allow sufficient gelant squeeze into the fractures and near-complete sealing of large fractures.

It is important to note, however, that the selection of chemicals and the design of fluids are case sensitive and reservoir rock-fluid properties, temperature, pressure, and saturation properties must be taken into considerations. However, there are a few criteria that need to be considered before trying this technology in a field. A general guideline is suggested next, and the actual treatment procedure has to be assured, based on individual reservoir and well parameters before implementation.

- It is worth reminding at this stage that this technology is developed for water shutoff in long horizontal wells where the water flow path is natural or artificial fractures connected to the water source. Reliable information on the location and geometry of the fractures, fracture aperture size distribution (Fig. 3), and the fractures which are responsible for water channeling must be ascertained through formation imaging logs such as FMI logs (Fig. 4) correlated with multi-array production logs. The selection of the bridging particles and the design of the oil zone protection fluid (Fluid-1) should be based on this information.

- Information on permeability and porosity contrast between oil-saturated and water-saturated zones must be available for the treatment fluid design and optimum squeeze pressure calculation.

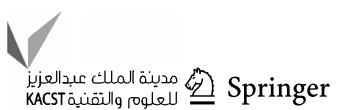


- Note that if both oil and water are produced from the same fractures, then this technology is not applicable (typically, within the transition zone or close to it).

- The well completion would play a crucial role in designing the treatment process. If the well is completed open hole, treatment through coil tubing and well segmentation with the help of a through tubing inflatable packer in combination with a retrievable bridge plug would be necessary. Segmented treatment may not be possible for pre-perforated liner completion unless completed with an external casing packer.

- For fluid placement, it is important to optimize the viscosity of the blocking gel as well as the filter cake forming fluid. In order to have a successful, effective well treatment, the candidate well should be studied in terms of reservoir pressure and the tendency for fluid loss.

- Plotting of real-time injection pressure versus gelant volume injection data (Hall plot) would help in deciding the limit of gelant injection. The upward deviation of the plot would indicate the filling of fracture volume.

- Since the return permeability/well productivity would depend on the efficiency of wellbore cleanup, the cleanup fluid composition and the soaking period must be well optimized.

\section{Conclusions}

High water cut in tight highly fractured carbonate reservoirs is a very common problem that contributes to low recovery factor and undesirable water production. This problem has significantly increased operating costs and reduced revenues from such reservoirs. Though this problem has attracted lots of attention from the research community, this problem is still unresolved! In this study, we developed an excellent treatment methodology consisting of a three-fluid system. The design is proven experimentally, demonstrating a significant reduction of water cut, allowing oil to flow freely through the tight matrix domain. The introduced technique is simple to prepare and apply by three steps (seal/squeeze/ clean). Simply, inject the sealant to protect the matrix domain that contains the large amount of residual oil, then inject the temperature-stable cross-linking gelant that fills the undesirable fractures and prevent water from flowing, and finally, inject the clean-up agent to break the coating film that protected the matrix domain, hence allowing the oil to flow. Although still in the laboratory stage, the study presents a novel idea that has been proven working, especially in high aperture fractures, which contributes most to the water flow. This technology could be promising, nevertheless needed to be optimized via a simulation study and pilot testing before it can be considered ready for field-scale application. The key findings from this study are:
- The developed fracture sealing gel is robust and maintained its mechanical strength at $100{ }^{\circ} \mathrm{C}$ for more than 60 days of observation.

- Ceramic disk tests show that the cleanup fluid can remove up to $98 \%$ of the residual cake from its surface, indicating high post-treatment return permeability.

- The return permeability of the two low fracture aperture cores was high after gel treatment with Frr value between 2 and 47, compared to the two larger apertures fractured cores with the Frr value of 12,000-64,000, respectively, indicating effective plugging of the large fractures.

- Critical gel extrusion pressure, an indication of blocking capacity of the gel, is found to be low for low aperture fractures (57 and $39 \mathrm{psi} / \mathrm{ft}$, respectively) compared to larger aperture fractures which are 256 and $164 \mathrm{psi} / \mathrm{ft}$, respectively, which is significantly higher than the pressure gradient available at the near-wellbore region.

Acknowledgements The authors sincerely acknowledge the Khalifa University of Science and Technology for the support and encouragement provided in undertaking this study.

\section{Compliance with ethical standards}

Conflict of interest The authors hereby declare no competing financial interests.

Open Access This article is licensed under a Creative Commons Attribution 4.0 International License, which permits use, sharing, adaptation, distribution and reproduction in any medium or format, as long as you give appropriate credit to the original author(s) and the source, provide a link to the Creative Commons licence, and indicate if changes were made. The images or other third party material in this article are included in the article's Creative Commons licence, unless indicated otherwise in a credit line to the material. If material is not included in the article's Creative Commons licence and your intended use is not permitted by statutory regulation or exceeds the permitted use, you will need to obtain permission directly from the copyright holder. To view a copy of this licence, visit http://creativecommons.org/licenses/by/4.0/.

\section{References}

Alaa AD et al (2008) Horizontal water shut-off for better production optimization and reservoir sweep efficiency (case study). Paper SPE 117066

Alaa AD et al (2013) Utilizing fiber optic enabled coil tubing telemetry in extended reach horizontal well mechanical rigless water shutoff (WSO) operation-case study. Paper SPE 149121

Al-Shabibi $\mathrm{H}$ et al (2012) Comprehensive diagnostic and water shut-off in open and cased hole carbonate horizontal wells. SPE-162287

Al-Zubail MA et al (2003) Rigless water shut-off experience in offshore Saudi Arabia. SPE-81443

Bedaiwi E et al (2009) Polymer injection for water production control through permeability alteration in fractured reservoir. NAFTA 60(4):221-231 
Belhaj HA et al (2003) Numerical and experimental modeling of nondarcy flow in porous media. SPE 81037

BP (1996) Sealing microfractured formations: quick reference guidelines

Burrafato G et al (1999) Rigless WSO treatments in gas fields. Bull heading gels and polymers in shaly sand: Italian case histories. SPE-54747

Chauveteau G et al (2004) Disproportionate permeability reduction by soft preformed microgels. Paper SPE 89390

Cheung SK, Quilter RM (1998) Design and implementation of a gel treatment to shut off water in a high temperature, high-pressure fractured reservoir. SPE-49075

Dabiri A et al (2017) Simulation study of controlling water coning in oil reservoirs through drilling of horizontal wells. Chem Eng Commun Biosci Biotechnol Res Commun 10(1):132-136

Dick MA et al (2000) Optimizing the selection of bridging particles for reservoir drilling fluids. SPE 58793

El-Karsani et al (2014) Polymer systems for water shutoff and profile modification: a review over the last decade. SPE J 19(01):135-149

Fang F et al (2017) Experimental study on the physical simulation of water invasion in carbonate gas reservoirs. Appl Sci 7:697-708

Hardy MB et al (1998) New organically cross-linked polymer system provides competent propagation at high temperatures in conformance treatments. SPE 39690

He WW, Stephens MP (2011) Bridging particle size distribution in drilling fluid and formation damage. SPE-143497

Inamullah et al (2015) Designing of FRAC flow model in naturally fracture reservoir for reducing water conning mechanism. (IFEDC 2015) Paper no. IFEDC2015492, pp 1-7. https://doi.org/10.1049/ cp. 2015.0583

Johnson Jr LA (1998) Production well water shut-off treatment in a fractured sandstone reservoir. OSTI ID: 788094. Report no. FC26-98FT40323-03

Liang J et al (1993) Placement of gels in production wells. SPE Prod Facil 8(04):276-284

Lymar IV (2011) Review of new water shut-off technologies implemented on the oil fields of the Republic of Belarus. Oil Gas Bus 2011(5):133-142

Mehtar MA et al (2012) Derivation of kinetic rate constant of enzymebuffer mud cake clean up systems-Laboratory investigation and verification in high temperature fractured carbonate reservoir. SPE 161643

Nasr-El-Din HA et al (1998) Field application of gelling polymers in Saudi Arabia. SPE 39615
Perez EM et al (2012) Water coning in naturally fractured carbonate heavy oil reservoir-a simulation study. SPE 152545

Reda AA (2016) Evaluation of water coning phenomenon in naturally fractured oil reservoirs. J Petrol Technol. https://doi.org/10.1007/ s13202-015-0185-7

Rushmore Reviews (2017) https://login.rushmorereviews.com

Salimi S, and Alikarami R (2006) Mechanism of fluid invasion in naturally fractured reservoirs: experimental study. SPE 98292

Sarkar S et al (2002) Fluid flow simulation in fractured reservoirs. Massachusetts Institute of Technology, Cambridge

Satter A, Iqbal GM (2016) "Horizontal well technology and performance" in Reservoir Engineering, Gulf Publishing Company

Seright RS (1995) Improved techniques for fluid diversion in oil recovery processes. Second annual report (DOE/BC/14880-10), U.S. DOE, pp 51-64

Seright RS (2003) Washout of Cr(III)-acetate-HPAM gels form fractures. SPE 80200

Sharifpour E et al (2015) Smart technique in water shutoff treatment for a layered reservoir through an engineered injection/production scheme. Ind Eng Chem Res 54(44):11236-11246

Taoutaou S (2013) Qualification of specialized cement to inflate bridge plug for water shutoff application in horizontal wells. SPE 163898

Turner B, Nwaozo J (2010) Quantitative evaluation of aquifer diversion to surrounding wells after multiple large polymer gel water shutoff treatment. SPE 132979

Whaley J (2008) Mali: a country on the cusp? Geoexpro 5(4):2008

Xianchao C et al (2014) Performance prediction of gel water shutoff in horizontal wells using a newly coupled reservoir-wellbore model. J Energy Resour Technol 136(2):229031-7

Yadav S et al (2013a) Investigating the effect of several parameters on the gelation behavior of partially hydrolyzed polyacrylamide-hexamine-hydroquinone gels. Ind Eng Chem Res 52(28):9532-9537

Yadav S et al (2013b) Modeling of partially hydrolyzed polyacrylamide-hexamine-hydroquinone gel system used for profile modification jobs in the oil field. J Pet Eng. 2013:1-11

Publisher's Note Springer Nature remains neutral with regard to jurisdictional claims in published maps and institutional affiliations. 